\title{
The carbon starvation stimulon in the marine Vibrio sp. S14 (CCUG 15956) includes three periplasmic space protein responders
}

\author{
LOUISE HolmQuist and STAFFAN KJELlEBerG*
}

Department of General and Marine Microbiology, University of Göteborg, Carl Skottbergs Gäta 22, S-413 19 Göteborg, Sweden

(Received 20 March 1992; revised 8 October 1992; accepted 19 October 1992)

\begin{abstract}
Growth arrest and long-term starvation in the marine Vibrio sp. S14 induce alterations of the cell envelope as well as a sequential expression of starvation-specific polypeptides. The induction and accumulation of three dominant carbon-starvation-induced periplasmic space protein responders of molecular mass 120 (Csp1), 37 (Csp5) and $30 \mathrm{kDa}$ (Csp6), were examined under different starvation and stress conditions. All three proteins were increasingly synthesized in response to carbon and multiple-nutrient starvation, but not during nitrogen and phosphorus starvation, nor in response to the imposition of stress conditions. Csp1 exhibited a more than 100-fold increased relative induction by carbon and multiple-nutrient starvation and was continuously synthesized throughout the experiment. Induction of Csp1 was completely repressed by all conditions other than carbon starvation. A less than fivefold increase in induction was monitored for the transient responders Csp5 and Csp6 within the first few hours of carbon starvation. Interestingly, Csp6 exhibited an increased transient induction at the onset as well as after $24 \mathrm{~h}$ of starvation. Accumulation of the three proteins was monitored by Western blot analysis using specific antisera. Of the conditions tested, long-term accumulation of these proteins was only detected when Vibrio sp. S14 cells were exposed to carbon and multiple-nutrient starvation. These results are discussed in relation to the recent finding that formation of starvation- and stress-resistant marine Vibrio is induced by carbon but not nitrogen or phosphorus starvation, and that Csp1, Csp5 and Csp6 will allow detailed studies of the carbon starvation stimulon.
\end{abstract}

\section{Introduction}

Nearly all ecosystems are oligotrophic, which means that any micro-organism, indigenous or introduced, must face periods with a shortage of energy. To survive under substrate-limiting conditions in marine waters some nondifferentiating bacteria respond to starvation by the formation of ultramicrocells, and when appropriate and sufficient nutrients are available they immediately start to grow and divide (Morita, 1988, 1990).

The marine non-differentiating heterotrophic Vibrio sp. S14 undergoes a series of morphological and physicochemical changes when exposed to starvation conditions. Several of these changes have been reported to occur in the cell envelope. For example, an enlarged periplasmic space during starvation, probably caused by an uneven shrinkage of the cytoplasmic membrane relative to the outer membrane, has been shown both for Vibrio sp. S14 (Mårdén et al., 1985) and Escherichia coli (Reeve et al.,

\footnotetext{
*Author for correspondence. Tel. 4631418700 ; fax 4631826790 .

Abbreviation: SHMT, serine hydroxamate.
}

1984). It has also been shown that Vibrio sp. S14 switches from low- to high-affinity uptake systems both for amino acids and sugars (Albertson et al., 1990c; Mårdén et al., 1987), similar to responses observed for Vibrio sp. ANT300 (Geesey \& Morita, 1979). Furthermore, starved Vibrio sp. S14 cells show an increased positive chemotaxis towards some amino acids and sugars during the initial few hours of starvation (Malmcrona-Friberg et al., 1990). Many of these alterations are dependent on de novo protein synthesis. Given the starvation-induced alterations in the periplasmic space characteristics, it is likely that this compartment may play a significant role in the physiology of stationary phase and starved cells.

De novo protein synthesis under starvation conditions has been intensively studied in the organisms Vibrio sp. ANT-300 (Amy \& Morita, 1983), E. coli (Groat et al., 1986), Salmonella typhimurium (Spector et al., 1986) and Vibrio sp. S14 (Nyström et al., 1988, 1990, 1992). These studies have generally focused on the global responses of the cell rather than the localization of the individual protein responders. Furthermore, the assumption that the successful development of starvation- and stressresistant cells of non-differentiating bacteria occurs 
independent of whether the cells are starved for carbon, nitrogen or phosphorus has focused the interest on general starvation proteins. It was demonstrated recently, however, that carbon rather than nitrogen or phosphorus starvation is the determinant for ultramicrocell formation. Hence, information on the carbon starvation stimulon and its specific member genes and proteins is needed. The present study is the first attempt to characterize such carbon-starvation-specific proteins in Vibrio. Three such specific responders in Vibrio sp. S14 were found to be located in the periplasm. The carbonstarvation-induced periplasmic space proteins, Cspl (120 kDa) (Albertson et al., 1987), Csp5 and Csp6, were studied at the level of induction and accumulation.

Characterization of the global regulatory networks, induced in starved cells, and their overlap provide further information on the starvation-induced adaptation programme. In the present study we report whether induction of Csp1, Csp5 and Csp6 occurs by exposure to the following stress conditions; heat shock, cold shock, oxidative stress, serine hydroxamate (SHMT) or $\mathrm{CdCl}_{2}$ addition, anaerobiosis and ethanol exposure. In addition, to test whether the polypeptides were induced also by catabolite repression, cAMP was added.

\section{Methods}

Organism, cultivation, starvation and stress conditions. The marine Vibrio sp. S14 (CCUG 15956) used in this study has been described previously (Albertson et al., 1990a; Mårdén et al., 1987). Based on biochemical determinations and 16S rRNA sequencing (S. Zabkar and others, unpublished data), it belongs to the core of the genus Vibrio. Vibrio sp. S14 cells were grown at $24^{\circ} \mathrm{C}$ on a rotary shaker in a marine minimal medium (MMM) (Östling et al., 1991) supplemented with $0.4 \%$ glucose. Vibrio sp. S14 has a growth rate of 0.9 doublings $h^{-1}$ under the conditions described. Cells were harvested in the exponential phase $\left(2.0 \times 10^{8}\right.$ cells $\left.\mathrm{ml}^{-1}, \mathrm{OD}_{610}=0.2\right)$ by centrifugation $(8000 \mathrm{~g}$, $10 \mathrm{~min}$ ), washed twice and resuspended in the appropriate starvation media. Starvation regimes were kept at $24^{\circ} \mathrm{C}$ on slow rotation.

Different nutrient limitations were achieved by resuspending the growing cells in growth medium lacking glucose, phosphorus, nitrogen, or all three nutrients, i.e. multiple-nutrient starvation. For the other stress conditions, aliquots of the exponentially growing cells were exposed to SHMT (10 mM), $\mathrm{CdCl}_{2}(500 \mu \mathrm{M})$, ethanol $(10 \%), \mathrm{H}_{2} \mathrm{O}_{2}$ $(60 \mu \mathrm{M})$, heat shock (shift from 24 to $40^{\circ} \mathrm{C}$ ), cold shock (shift from 24 to $5{ }^{\circ} \mathrm{C}$ ) and anaerobiosis $\left(\mathrm{N}_{2}\right.$ flush). cAMP was added at a concentration of $5 \mathrm{~mm}$ (Nyström et al., 1990).

Viability. Viability was measured by c.f.u. on VNSS agar (Väätänen, 1976) using the drop plate method (Hoben \& Somasegaran, 1982).

Pulse-labelling experiments, periplasmic space and whole cell protein preparation. During exposure for various starvation conditions, $15 \mathrm{ml}$ of the cell suspension was labelled for 10 min during $0,0 \cdot 5,3$ and $8 \mathrm{~h}$ starvation with $50 \mu \mathrm{Ci}\left[{ }^{35}\right.$ S]methionine (Dupont, New England $\mathrm{Nu}-$ clear; $1 \mathrm{Ci}=37 \mathrm{GBq})$. For the longer starvation periods $(24,48$ and $96 \mathrm{~h}$ ) the pulse lasted $20 \mathrm{~min}$. Pulse-labelling of stress-induced cells was made subsequent to a 10 min prestress period for the individual stress inducer. The cells were labelled for a period of $10 \mathrm{~min}$, except for the cold shock experiment where the cells had been chilled to $5{ }^{\circ} \mathrm{C}$ for
$50 \mathrm{~min}$ in a refrigerator before labelling. After labelling, cells were filtered onto $0.22 \mu \mathrm{m}$ membrane filters (Poretics), washed with the appropriate medium and resuspended in $1 \mathrm{ml}$ sterile distilled water and incubated for $15 \mathrm{~min}$. This allowed for osmotic shock release of the periplasmic space contents (Mårdén et al., 1987). Cells were centrifuged at $15000 \mathrm{~g}$ in a microfuge (Beckman). The supernatant, which contained the periplasmic space proteins, was filter sterilized $(0.22 \mu \mathrm{m})$ and lyophilized. [This method is highly reproducible and the osmotically shocked cells remain $100 \%$ viable. Furthermore, comparisons of the periplasmic fraction, and the cytoplasmic and membrane fractions by O'Farrell two-dimensional gel electrophoresis were performed (data not shown). Csp1, Csp5 and Csp6 cannot be found in the latter fractions.] A $50 \mu$ filtrate subsample was withdrawn before lyophilization to measure the amount of radioactivity incorporated into polypeptides by precipitation with $5 \%(\mathrm{w} / \mathrm{v})$ cold TCA. The precipitates were collected on membrane filters and resuspended in scintillation cocktail (Aquassure, NEN Dupont), and the radioactivity counts were determined using a scintillation counter (Beckman model LS $6000 \mathrm{LL}$ ). Extraction of whole cell protein was done by precipitation with TCA and the precipitation was processed as described above for determining radioactivity.

Gel electrophoresis. The periplasmic fractions were resuspended in $50 \mu \mathrm{l} 10 \mathrm{~mm}$-Tris/HCl $\mathrm{pH} 8.0$ and $10 \mu \mathrm{l}$ SDS-PAGE sample buffer and analysed by electrophoresis on $12 \%$ polyacrylamide gels using the Laemmli buffer system (LKB, Pharmacia). Fifty $\mu \mathrm{g}$ protein containing a known radioactivity was loaded on the gels. The separated proteins were transferred to nitrocellulose (Schleicher \& Schüell) by electroblotting using Mini-Protean and Mini-Transblot apparatus (BioRad), following the manufacturer's instructions. The electroblotted gels were stained with Coomassie brilliant blue G250 to check for $100 \%$ transfer. The membranes were subjected to autoradiography overnight and Western blot analysis was performed using the same membranes. Autoradiograms were scanned using a LKB Ultroscan XL 2220 densitometer at $633 \mathrm{~nm}$. The relative induction was calculated by dividing the absorbance of each band by the total radioactivity and length of the pulse loaded on the gel. Similarly, the relative amount and accumulation of the proteins were calculated by dividing the absorbance of each band by the protein concentration loaded on the gel.

Protein concentration measurements. An aliquot from each resuspended periplasmic fraction was used to measure the protein concentration. Twenty microlitres was analysed using the Pierce BCA microtitre assay protocol at $37^{\circ} \mathrm{C}$. Bovine serum albumin (BSA) was used as standard. Protein concentrations were determined by using a microtitre plate reader at $545 \mathrm{~nm}$ (Biotek Instruments model EL312e)

Antisera preparation and Western blot analysis. Ten preparative SDSPAGE gels $(1.5 \mathrm{~mm}$ thick) were run with periplasmic fractions from Vibrio sp. S14 cells that had been starved for carbon for $24 \mathrm{~h}$, using the Laemmli buffer system. The gels were stained with Coomassie brilliant blue G250 and the bands corresponding to Csp5 and Csp6 were cut out using a razor blade. The gel pieces were homogenized by sequentially squeezing through thinner gauge needles, the finest of which was 18 gauge. The homogenates of Csp5 and Csp6 so obtained were injected intradermally ( $50 \mathrm{mg}$ per injection) into two New Zealand white female rabbits four times, with 2 week interval between each injection. Freund's complete adjuvant was used for the first injection; thereafter we used Freund's incomplete adjuvant. Each antiserum obtained was used at a dilution of 1:2000. The antibody recognizing Csp1 was prepared by Albertson et al. (1987). For Western blotting we used the method recommended by the manufacturer (Stratagene, Picoblue immunoscreening kit), except that we used $2 \%$ (v/v) Tween-20 instead of BSA for blocking of background non-specific sites. An alkaline phosphatase-conjugated goat anti-rabbit antibody was used as the secondary antibody. 


\section{Results}

Incorporation of radiolabelled methionine in the periplasmic space proteins during starvation

Changes in the degree of incorporation of labelled methionine during different starvation regimes and at different times of starvation were measured by pulselabelling starved Vibrio sp. S14 cells (Fig. 1). Multiplenutrient starvation showed a less than threefold increase in the relative rate of incorporation, but it did not exhibit the secondary increase displayed by carbon-starved cells. Phosphorus starvation induced an immediate drop in protein synthesis prior to a return to the synthesis observed during growth conditions after $24 \mathrm{~h}$ of star-

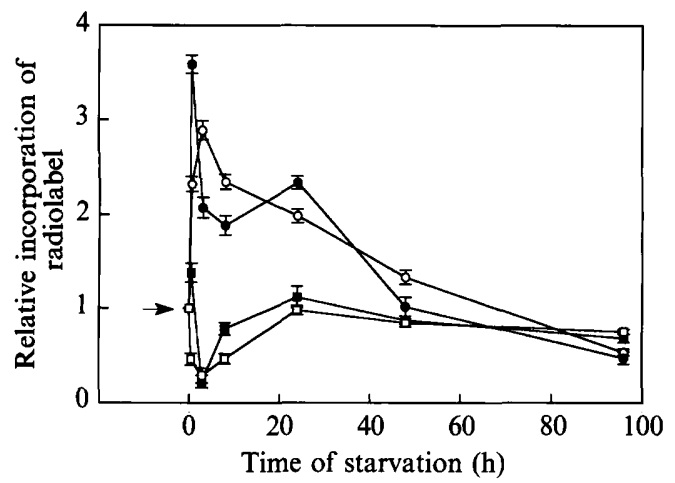

Fig. 1. Relative incorporation of radiolabelled methionine into the periplasmic space proteins of Vibrio sp. S14 during starvation \pm SD. Exponentially growing cells were assigned a value of $1 \cdot 0$. Starved cells were pulse-labelled, the periplasmic space proteins were precipitated and radioactive counts were determined in a liquid scintillator. The cells were exposed to either multiple-nutrient $(O)$, carbon $(O)$, nitrogen $(\square)$ or phosphorus $(\square)$ starvation. The arrow indicates the onset of starvation. The experiment was repeated four times to confirm reproducibility. vation. Nitrogen and phosphorus starvation gave a similar response. The amount of radioactivity incorporated into the periplasmic space proteins as a percentage of that incorporated into whole cell protein varied with different individual nutrients and times of starvation, increasing from 15 to $40 \%$ during the first $8 \mathrm{~h}$ of carbon starvation and stabilizing at $20 \%$ of total radioactivity in periplasmic space proteins after prolonged starvation. Multiple-nutrient-starved cells exhibited a maximum of $30 \%$ at $8 \mathrm{~h}$, whereas nitrogen and phosphorus starvation gave an increase from 15 to $25 \%$ during the first $8 \mathrm{~h}$ and a decrease to $10 \%$ during prolonged starvation. The fact that there were essentially no changes in the protein profile (Fig. 2) indicates that cytoplasmic proteins are not present as contaminants in the periplasmic space fraction, released by osmotic shock, at any of the starvation times tested.

\section{Relative induction of Csp1, Csp5 and Csp6 during starvation for different nutrients}

The relative induction of the periplasmic space proteins Csp1, Csp5 and Csp6 was measured by scanning the autoradiograms from the SDS-polyacrylamide gels which were loaded with the pulse-labelled periplasmic space proteins. The presence of a single protein per band was validated by O'Farrell two-dimensional gel electrophoresis (data not shown). Cspl was synthesized during carbon and multiple-nutrient starvation but was not detected during nitrogen or phosphorus starvation (Fig. $3 a$ ). It is noteworthy that the relative induction of Cspl increased more than 100 -fold within $24 \mathrm{~h}$ of carbon or multiple-nutrient-starvation. The pattern of induction for both Csp5 and Csp6 was similar in that starvation for nitrogen and phosphorus decreased protein synthesis,

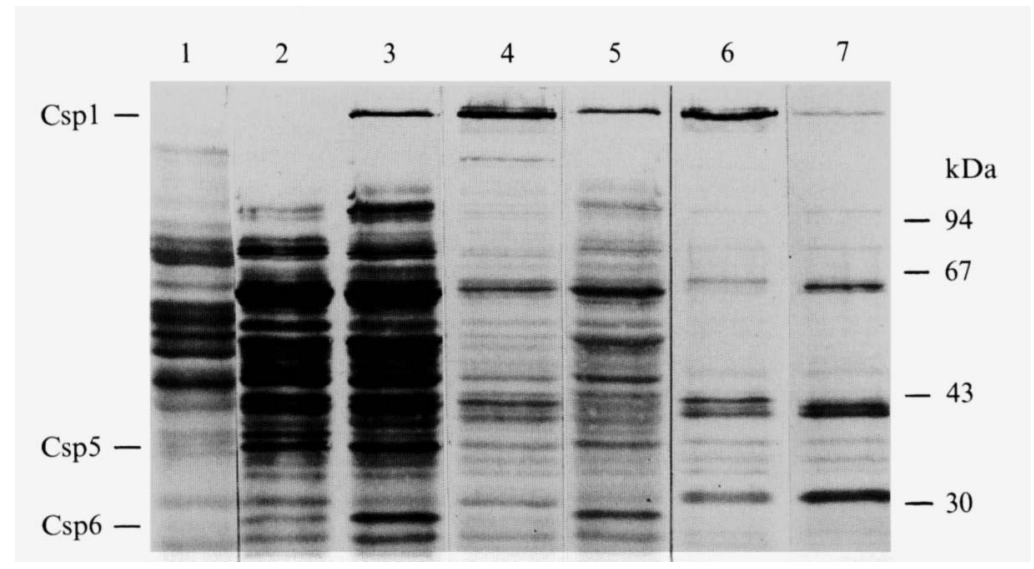

Fig. 2. A non-quantitative autoradiogram of a $12 \%$ SDS-polyacrylamide gel of periplasmic space proteins of Vibrio sp. S14 cells starved of carbon. The periplasmic space proteins Cspl, Csp5 and Csp6 are indicated. Lanes: 1, exponentially growing cells; $2,0.5 \mathrm{~h} ; 3,3 \mathrm{~h}$; $4,8 \mathrm{~h} ; 5,24 \mathrm{~h} ; 6,48 \mathrm{~h}$; and 7,96 h starvation. Standard molecular mass proteins are indicated. All lanes except lane 1 are from the same gel. Different exposure times were employed for the different lanes for better visualization. The experiment was repeated four times to confirm reproducibility; a representative result is shown. 

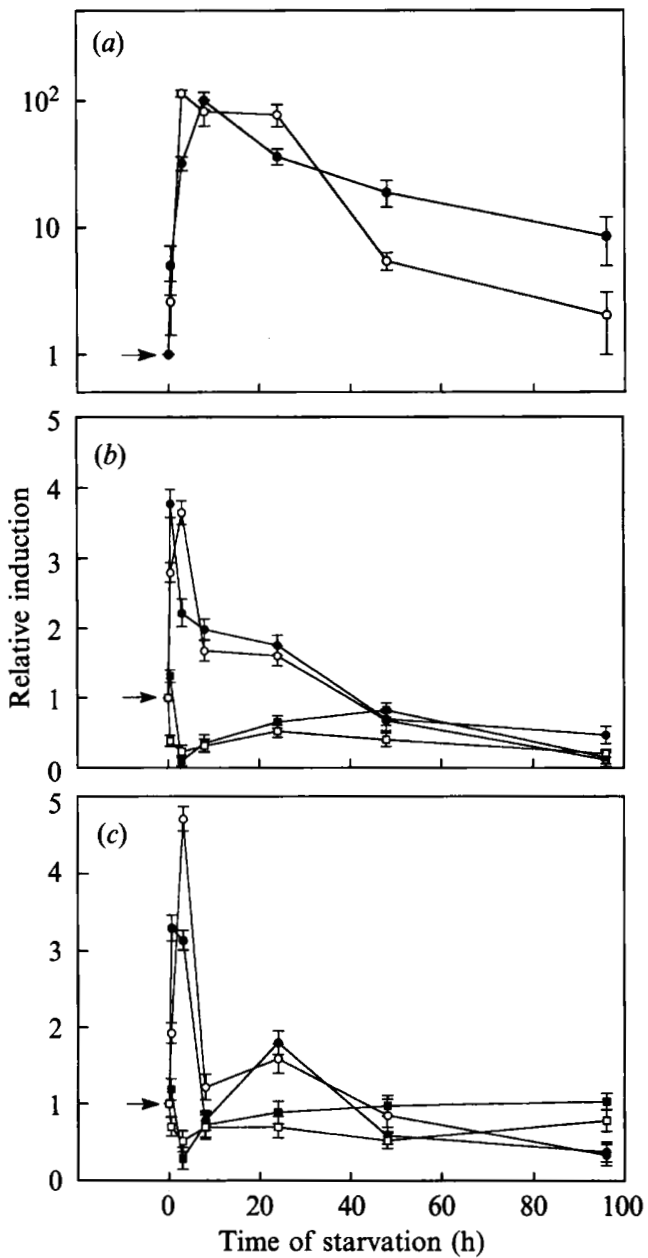

Fig. 3. Relative induction of the periplasmic space proteins Cspl (a), Csp5 (b) and Csp6 (c) in Vibrio sp. S14 during starvation \pm SD. Exponentially growing cells were assigned a value of $1 \cdot 0$. Starved cells were pulse-labelled and the periplasmic space proteins were separated by SDS-PAGE. Calculations were made from autoradiograms and scanning data (see Methods). The cells were exposed to either multiplenutrient $(\bigcirc)$, carbon $(\bigcirc)$, nitrogen $(\square)$ or phosphorus $(\square)$ starvation. The arrow indicates the onset of starvation. Synthesis of Csp1 during nitrogen and phosphorus starvation was not detected. The experiment was repeated four times to confirm reproducibility.

whereas starvation for multiple-nutrients and carbon increased protein synthesis (Figs $3 b$ and $c$ ). In contrast, carbon depletion induced synthesis of Csp5 in a manner similar to multiple-nutrient starvation (Fig. $3 b$ ), whereas multiple-nutrient starvation was found to be the dominant inducer for synthesis of Csp6 (Fig. 3c). Furthermore, there was a transient decrease in induction of Csp6 by $8 \mathrm{~h}$ of carbon starvation. The pattern of synthesis of Csp5 showed strong similarity with the pattern of synthesis of the pool of the periplasmic space proteins (Figs 1 and $3 b$ ). The molecular masses of Csp5 and Csp6 were found to be 37 and $30 \mathrm{kDa}$, respectively. A non-quantitative autoradiogram from a $12 \%$ SDSpolyacrylamide gel (Fig. 2) of a carbon starvation time
Table 1. Relative survival and synthesis of Csp5 and Csp6 in Vibrio sp. S14 during exposure to different stress conditions

Cells were pulse-labelled and the periplasmic space proteins were separated by SDS-PAGE. Data were calculated from scanned autoradiograms (see Methods). The relative degree of survival was measured by c.f.u. on VNSS agar. Data are given as relative values \pm SD, where untreated exponentially growing cells were assigned a value of 1.0 . The experiment was repeated four times to confirm reproducibility.

\begin{tabular}{|c|c|c|c|}
\hline \multirow{2}{*}{$\begin{array}{l}\text { Stress } \\
\text { exposure }\end{array}$} & \multirow{2}{*}{$\begin{array}{l}\text { Relative survival of } \\
\text { cells }\end{array}$} & \multicolumn{2}{|c|}{ Relative synthesis } \\
\hline & & Csp5 & Csp6 \\
\hline $5^{\circ} \mathrm{C}$ & $0.62 \pm 0.04$ & $0.87 \pm 0.05$ & $1.04 \pm 0.04$ \\
\hline $40^{\circ} \mathrm{C}$ & $0.40 \pm 0.03$ & $0.78 \pm 0.07$ & $1.08 \pm 0.03$ \\
\hline $\mathrm{N}_{2}$ & $0.98 \pm 0.01$ & $0.56 \pm 0.02$ & $0.45 \pm 0.01$ \\
\hline $\mathrm{CdCl}_{2}$ & $0.72 \pm 0.03$ & $0.38 \pm 0.03$ & $0.54 \pm 0.01$ \\
\hline SHMT & $0.96 \pm 0.02$ & $0.68 \pm 0.06$ & $0.72 \pm 0.02$ \\
\hline Ethanol & $0.54 \pm 0.04$ & $0.23 \pm 0.04$ & $0.34 \pm 0.02$ \\
\hline cAMP & $0.86 \pm 0.06$ & $0.74 \pm 0.05$ & $0.88 \pm 0.02$ \\
\hline $\mathrm{H}_{2} \mathrm{O}_{2}$ & $0.20 \pm 0.03$ & 0.00 & 0.00 \\
\hline
\end{tabular}

course shows the induction of the specific proteins in the periplasmic fraction of Vibrio sp. S14.

Survival of Vibrio sp. S14 and synthesis of Csp1, Csp5 and Csp6 under different stress conditions

To investigate whether the induction of Csp1, Csp5 or Csp6 by exposure to other stress conditions overlaps with carbon and multiple-nutrient starvation, we challenged exponentially growing cells with ethanol, $\mathrm{CdCl}_{2}$, heat shock, cold shock, anaerobic conditions $\left(\mathrm{N}_{2}\right)$ and oxidative stress $\left(\mathrm{H}_{2} \mathrm{O}_{2}\right)$, as well as with added SHMT and cAMP. The cells were tested for viability (c.f.u.) immediately after the stress exposure was terminated, and periplasmic space proteins were prepared and analysed by gel electrophoresis (Table 1). The largest decrease in survival was observed when the cells were exposed to heat and oxidative stress : 40 and $20 \%$ of the original number of cells remained viable, respectively. No synthesis of Csp1 was detected for any of the stress conditions tested. Except for oxidative stress, synthesis of Csp5 and Csp6 occurred under all stress conditions, but did not exceed the rate of synthesis of the untreated cells.

\section{Detection of Csp1, Csp5 and Csp6 using antibodies during different starvation and stress conditions}

Western blotting was performed using the same membranes as those used for autoradiography. This certifies that the band detected by the antibody can be identified on the autoradiogram. Since we loaded equal amounts of protein on the gels, the intensity of the bands on the 


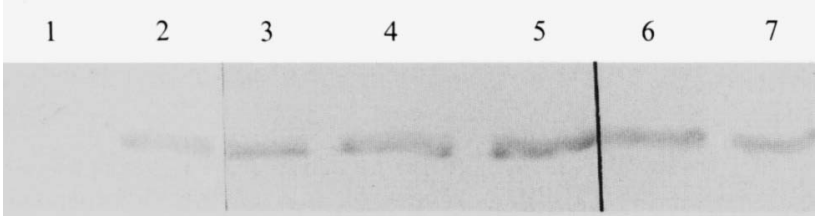

Fig. 4. A Western blot showing the periplasmic space protein Csp5 of Vibrio sp. S14, detected by anti-Csp5 during a carbon starvation time course experiment. Lanes: 1, exponentially growing cells; $2,0.5 \mathrm{~h} ; 3$, $3 \mathrm{~h} ; 4,8 \mathrm{~h} ; 5,24 \mathrm{~h} ; 6,48 \mathrm{~h} ;$ and $7,96 \mathrm{~h}$ starvation. The experiment was repeated four times to confirm reproducibility; a representative result is shown.

Table 2. Relative accumulation of Csp1, Csp5 and Csp6 in Vibrio sp. S14 detected with specific antibodies

Western blot analysis was performed on periplasmic space proteins of cells starved for carbon. Data are presented as relative values $\pm \mathrm{SD}$, where exponentially growing cells were assigned a value of $1 \cdot 0$. The experiment was repeated four times to confirm reproducibility.

\begin{tabular}{cccc}
\hline \hline \multirow{2}{*}{$\begin{array}{c}\text { Time of } \\
\text { starvation } \\
\text { (h) }\end{array}$} & Csp1 & Csp5 & Csp6 \\
\cline { 2 - 4 } & $1 \cdot 40 \pm 0 \cdot 13$ & $4 \cdot 11 \pm 0 \cdot 16$ & $3 \cdot 76 \pm 0 \cdot 06$ \\
$0 \cdot 5$ & $3 \cdot 18 \pm 0 \cdot 02$ & $4 \cdot 79 \pm 0.01$ & $4 \cdot 06 \pm 0 \cdot 08$ \\
3 & $7 \cdot 56 \pm 0.09$ & $5 \cdot 41 \pm 0 \cdot 16$ & $4 \cdot 64 \pm 0 \cdot 06$ \\
8 & $8 \cdot 40 \pm 0 \cdot 14$ & $6 \cdot 46 \pm 0.06$ & $5 \cdot 86 \pm 0 \cdot 09$ \\
24 & $2 \cdot 42 \pm 0 \cdot 12$ & $7 \cdot 08 \pm 0 \cdot 12$ & $4 \cdot 14 \pm 0 \cdot 09$ \\
48 & $2 \cdot 28 \pm 0 \cdot 01$ & $6 \cdot 36 \pm 0.09$ & $3 \cdot 87 \pm 0 \cdot 10$ \\
96 & & & \\
\hline \hline
\end{tabular}

Western blots, given by scanning with a densitometer, allows for comparative studies. Table 2 shows the accumulation of Csp1, Csp5 and Csp6 during carbon starvation, identified by the antibodies raised against the specific proteins. The concentration of Cspl decreased during prolonged carbon starvation although synthesis continued, indicating increased degradation of the protein. Whilst there was little or no synthesis of Csp5 and Csp6 after $48 \mathrm{~h}$ of carbon starvation, the concentration of these proteins was high, probably due to the low rate of degradation of these proteins. The multiple-nutrient starvation experiment showed essentially the same pattern of protein accumulation as did carbon starvation, whereas for nitrogen and phosphorus starvation, as well as for the different stress conditions tested, no accumulation could be detected (data not shown). Fig. 4 shows a typical Western blot, using antiCsp5, of a carbon starvation time course experiment.

\section{Discussion}

It was recently established that the starvation-induced adaptation programme in Vibrio sp. S14 is identical, with respect to the macromolecular synthesis pattern, viability and induction of cross protection against a variety of stress agents, whether induced by multiple-nutrient or carbon starvation (Nyström et al., 1992). Whilst nitrogen and phosphorus starvation induce the same programme as does carbon starvation, and successfully develop starvation- and stress-resistant small starved cells in $E$. coli (Matin, 1991) and Bacillus subtilis (Hecker \& Völker, 1990; Losick \& Youngman, 1984), the response exhibited by Vibrio is clearly very different. The present study confirms the finding reported by Nyström et al. (1992) that nitrogen and phosphorus starvation give rise to a different response as compared to carbon and multiplenutrient starvation. Whilst no loss in viability, compared to the onset of starvation, was observed for the latter starvation conditions in the present study, $96 \mathrm{~h}$ nitrogenand phosphorus-starved cells exhibited a $>99.9 \%$ loss in c.f.u. (data not shown). The loss of viability when the cells are starved for nitrogen or phosphorus is probably due to the inability of the cells to divide and form colonies, however, rather than cell death (unpublished).

The only differences observed between multiplenutrient and carbon starvation in this study are those of the time and extent of maximum synthesis of the pool of proteins in the periplasmic space (Fig. 1), the percentage of radiolabelled periplasmic space proteins compared to radiolabelled whole cell protein, and synthesis of the three individual proteins. In view of these findings, it is suggested that an improved understanding of the starvation-induced adaptation response in marine Vibrio will be gained by studies of the carbon starvation stimulon and its member responders rather than those proteins that are induced irrespective of carbon, nitrogen or phosphorus starvation. The carbon starvation network may regulate the adaptation programme and development of starvation- and stress-resistant cells.

This study shows that the periplasmic space proteins Csp1, Csp5 and Csp6 are induced by carbon as well as multiple-nutrient starvation, but not by nitrogen and phosphorus depletion. As with the pex genes in E. coli, which are essential for development of starvation and stress resistance (Matin, 1991), the genes encoding Cspl, Csp5 and Csp6 are cAMP-independent. As for the total protein synthesis of the periplasmic space polypeptides, the initial phase of nitrogen and phosphorus starvation appears to repress rather than induce synthesis of Csp5 and Csp6. Very importantly, the three Csp proteins appear to represent carbon starvation-specific responders that are induced at different times of the adaptation programme. The sequential induction of carbon starvation genes of this programme can therefore be studied. Cspl exhibits a $>100$-fold increase in its rate of synthesis by $8 \mathrm{~h}$ of carbon starvation. A three- to fourfold increase in synthesis for Csp5 and Csp6 peaked after $3 \mathrm{~h}$ starvation. The latter proteins were transient responders: 
by $48 \mathrm{~h}$ of carbon and multiple-nutrient starvation the rate of synthesis was as low as that observed at the onset of starvation. Cspl appears to be synthesized throughout the entire period of starvation and belongs to the subclass of class A protein responders that are permanently induced during prolonged periods of non-growth (Nyström et al., 1990). However, Csp5 and Csp6 remain stable, as shown by Western blot analysis, throughout the starvation period of $96 \mathrm{~h}$ employed in this study. Again, the multiple-nutrient and carbon starvationinduced cells showed an almost identical pattern of accumulation, whereas the Western blot analysis did not detect any accumulation of Csp1, Csp5 and Csp6 for nitrogen- or phosphorus-starved cells.

It is in fact feasible that the three periplasmic space proteins examined in this study belong exclusively to the carbon starvation stimulon. In addition to the lack of induction by nitrogen and phosphorus starvation, neither amino acid starvation (SHMT addition), cAMP addition or any of the six stress conditions evoked an increased synthesis of Csp1, Csp5 and Csp6. Further studies of these as well as the regulation of the encoding genes may therefore provide a tool for elucidating the starvationinduced adaptation and formation of small starved cells in marine Vibrio strains.

As deduced from the pronounced alterations observed in cell-envelope-related characteristics of starving cells, it is likely that several of the 66 starvation-induced genes detected during the initial few days of multiple-nutrient starvation direct the synthesis of proteins, the destination of which is the periplasmic space. Whilst several studies of starvation-specific protein responders have been reported for E. coli, S. typhimurium and marine Vibrio strains (Amy \& Morita, 1983; Groat et al., 1986; Nyström et al., 1988, 1990, 1992; Spector et al., 1986), few attempts have been made to assign these responders to a cellular location. In one such study, Nyström et al. (1988) identified starvation-specific proteins in the periplasmic space of Vibrio sp. S14 which were sequentially induced over a period of $24 \mathrm{~h}$ multiple-nutrient starvation.

Observations on starvation-induced phenotypic alterations have revealed a series of changes that most likely reflect shifts in the protein composition of the periplasmic space of different Vibrio strains. The induction of high affinity uptake systems for amino acids and sugars has been described at various times after growth arrest (Albertson et al., 1990c; Geesey \& Morita, 1979; Mårdén et al., 1987). The identification of the binding proteins involved in these responses has also been reported. Several studies have demonstrated starvation-specific alterations in chemotaxis towards amino acids and sugars (Malmcrona-Friberg et al., 1990), which possibly involve binding proteins for delivery of the attractant to the membrane-bound transducer. Additional periplasmic-space-localized starvation proteins are exoproteases. It has been demonstrated that an increased exoprotease activity correlates with the growth-arrestinduced differentiation response in two marine bacterial strains (Albertson et al., 1990a). Such an activity is most likely to stimulate the cell to induce new uptake systems that allow the cell to mobilize substrates otherwise inaccessible to them.

The molecular masses of Csp5 and Csp6 were found to be 37 and $30 \mathrm{kDa}$, respectively. Interestingly, these are within the size range of most binding proteins of Gramnegative bacteria (22-41 kDa; Philips et al., 1987). We have not yet been able to assign a function to the periplasmic space proteins Csp1, Csp5 and Csp6. Nterminal sequences of these proteins have been made and these do not start with methionine, indicating cleaved signal sequences (data not shown). Homologies with other proteins in available databases have not been found. The gene encoding Csp5 has been cloned and is presently being sequenced (unpublished). This, as well as cloning and sequencing of Csp1 and Csp6, will allow us to identify regulatory regions of carbon-starvationspecific genes that are transcribed at different times of the adaptation programme and generate site-specific mutants in order to further understand the function of carbon-starvation-specific proteins.

It is worth mentioning that one of three carbonstarvation-specific periplasmic space proteins, Csp1, was identified as the product of an mRNA species with a functional half-life of $71 \mathrm{~min}$ after $24 \mathrm{~h}$ of multiplenutrient starvation (Albertson et al., 1990 b). Antibodies raised against 24 -h-starved cells were previously found to specifically detect a limited number of outer membrane and periplasmic space proteins (Albertson et al., 1987), one of which was subsequently identified as the product of the long-lived Csp1 mRNA transcript (Albertson et $a l ., 1990 \mathrm{~b}$ ). The induction of long-lived transcripts may represent one way for the cell to regulate and minimize the cost for synthesis of essential proteins during starvation.

This study was supported by a grant from the Swedish Natural Science Research Council.

\section{References}

Albertson, N. H., Jones, G. W. \& KJelleberg, S. (1987). The detection of starvation-specific antigens in two marine bacteria. Journal of General Microbiology 133, 2225-2231.

Albertson, N. H., Nyström, T. \& KJelleberG, S. (1990a). Exoprotease activity of two marine bacteria during starvation. Applied and Environmental Microbiology 56, 218-223.

Albertson, N. H., NySTRÖM, T. \& KJelleberG, S. (1990 b). Functional mRNA half-lives in the marine Vibrio sp. S14 during starvation and recovery. Journal of General Microbiology 136, 2195-2199. 
Albertson, N. H., NYSTRÖM, T. \& KJELlEBerG, S. (1990c). Starvationinduced modulations in binding protein-dependent glucose transport by the marine Vibrio sp. S14. FEMS Microbiology Letters 70, 205-210.

AmY, P. S. \& Morita, R. (1983). Protein patterns of growing and starved cells of a marine Vibrio sp. Applied and Environmental Microbiology 45, 1748-1752.

GeEsey, G. G. \& Morita, R. Y. (1979). Capture of arginine at low concentrations by a marine psychrophilic bacterium. Applied and Environmental Microbiology 38, 1092-1097.

Groat, R. G., Schultz, J. E., ZyChlinsky, E., Bockman, A. \& MATIN, A. (1986). Starvation proteins in Escherichia coli: kinetics of synthesis and role in starvation survival. Journal of Bacteriology 168, 486-493.

HeCKER, M. \& VöLKER, U. (1990). General stress proteins in Bacillus subtilis. FEMS Microbiology Ecology 74, 197-213.

Hoben, H. J. \& Somasegaran, P. (1982). Comparison of the pour, spread and the drop plate methods for enumeration of Rhizobium spp. in inoculants made from presterilized peat. Applied and Environmental Microbiology 44, 1246-1247.

Losick, R. \& Youngman, P. (1984). Endospore formation in Bacillus. In Microbial Development, pp. 63-88. Edited by R. Losick \& L. Shapiro. Cold Spring Harbor, NY: Cold Spring Harbor Laboratory.

MalmCrona-Friberg, K., Goodman, A. \& KJelleberg, S. (1990). Chemotactic responses of a marine Vibrio sp. strain S14 (CCUG 15956) to low-molecular-weight substances under starvation-survival conditions. Applied and Environmental Microbiology 56, 3699-3704.

Mårdén, P., Nyström, T. \& KJElleberg, S. (1987). Uptake of leucine by a marine Gram-negative heterotrophic bacterium during exposure to starvation conditions. FEMS Microbiology Ecology 45, 233-241.

Mårdén, P., Tunlid, A., MalmCrona-Friberg, K., Odham, G. \& KJelleberg, S. (1985). Physiological and morphological changes during short term starvation of marine bacterial isolates. Archives of Microbiology 142, 326-332.

MatiN, A. (1991). The molecular basis of carbon-starvation-induced general resistance in Escherichia coli. Molecular Microbiology 5, 3-10.
MoRITA, R. Y. (1988). Bioavailability of energy and its relationship to growth and starvation survival in nature. Canadian Journal of Microbiology 34, 436-441.

MORITA, R. Y. (1990). The starvation-survival state of microorganisms in nature and its relationship to the bioavailable energy. Experientia 46, 813-817.

NyströM, T., Albertson, N. \& KJElleberg, S. (1988). Synthesis of membrane and periplasmic proteins during starvation of a marine Vibrio sp. Journal of General Microbiology 134, 1645-1651.

NySTRÖM, T., FlärdH, K. \& KJELLEBERG, S. (1990). Responses to multiple-nutrient starvation in marine Vibrio sp. strain CCUG 15956. Journal of Bacteriology 172, 7085-7097.

Nyström, T., Olsson, R. M. \& KJeLleberg, S. (1992). Survival, stress resistance, and alterations in protein expression in the marine Vibrio sp. S14 during starvation for different individual nutrients. Applied and Environmental Microbiology 58, 55-65.

Östling, J., Goodman, A. \& KJelleberg, S. (1991). Behaviour of IncP-1 plasmids and a miniMu transposon in a marine Vibrio sp.: isolation of starvation-inducible lac operon fusions. FEMS Microbiology Ecology 86, 83-94.

Philips, T. A., Vaughn, V., Bloch, P. L. \& Neidhardt, F. C. (1987). Gene protein index of Escherichia coli K-12, edition 2. In Escherichia coli and Salmonella typhimurium, Cellular and Molecular Biology, pp. 919-966. Edited by F. C. Neidhardt, J. O. Ingraham, K. Brooks Low, B. Magasanik, M. Schaechter \& H. E. Umbarger. Washington, D.C.: American Society for Microbiology.

ReEve, C. A., AMY, A. S. \& MATIN, A. (1984). Role of protein synthesis in the survival of carbon starved Escherichia coli K-12. Journal of Bacteriology 160, 1041-1046.

Spector, M. P., Aliabadi, Z., Gonzalez, T. \& Foster, J. W. (1986). Global control in Salmonella typhimurium: two-dimensional electrophoretic analysis of starvation-, anaerobiosis-, and heat shockinducible proteins. Journal of Bacteriology 168, 420-424.

VÄÄTÄNEN, P. (1976). Microbiological studies in coastal waters of the Northern Baltic sea. I. Distribution and abundance of bacteria and yeasts in the Tvärminne area. Walter and Andre de Nottbeck Foundation Scientific Report. 1, 1-58. 